\title{
Optimization with Taguchi Method of Influences on Surface Roughness of Cutting Parameters in CNC Turning Processing
}

\author{
Mustafa ÖZDEMIR \\ Department of Machine and Metal Technology, Vocational School of Technical Sciences, Yozgat Bozok University, \\ Yozgat, Turkey,E mail: mustafa.ozdemir@bozok.edu.tr \\ crossref http://dx.doi.org/10.5755/j01.mech.25.5.23005
}

\section{Introduction}

Forming the metals by machining is the basis of the manufacturing sector. The low investment costs, the long service life of the machines and lathes, suitability of the processing parameters to optimization, and most importantly, the good surface quality and dimensions of the obtained products are some of the reasons for the preference of machining over the other production methods $[1,2]$. There are many parameters that affect the surface roughness values, such as tool-material pair and cutting parameters. Surface roughness is defined as irregularities occurring on the surface of the machined material. It is usually shown by the symbols $R a$ (mean roughness) and $R z$ (height between the peak and the pit). For this reason, it is very important to optimize the processing parameters and to reveal the appropriate processing conditions [2-4].

When the studies on the surface roughness in the literature are evaluated; In their study, Yang et al., investigated the test results obtained by using cutting parameters such as cutting speed, feed rate, and depth of cut for finish turning of Titanium alloy material with Response Surface Methodology (RSM) [5]. Selvaraj, effects of cutting parameters (cutting speed, feed rate and depth of cut) on the surface roughness were analyzed using Taguchi technique. The results revealed that the feed rate is the most important parameter affecting the surface roughness, followed by cutting speed and depth of cut [6]. Yan et al., investigated parametrically the effects of cutting speed, depth of cut, and cutting tool nose type in machining of hardened AISI H13 steel via numerical simulation [7]. Yücel and Günay optimized the cutting conditions for the average surface roughness and cutting force values in hard turning process. Hard turning experiments were designed with the Taguchi L18 orthogonal array [8]. Sahoo applied Taguchi and regression analysis on the surface roughness results in machining of hardened AISI D2 steel. The model prepared for the estimation of surface roughness was designed according to L27 orthogonal array [9]. Bouacha et al., conducted a study on the statistically analysis of surface roughness and cutting forces using RSM in hard turning of AISI 52100 bearing steel. The effect of cutting forces and cutting parameters affecting surface roughness was analysed by ANOVA [10]. Özlü et al., experimentally investigated the effects of cutting parameters of 30MnVS6 micro alloyed steel on surface roughness and cutting forces in CNC turning lathe [11]. Fnides et al. study to determine statistical models of surface roughness in turning hardened AISI H11 steel (50 HRC) with mixed ceramic tool [12]. Bouzid et al. analyzed the results of the effect of cutting speed, feed rate and depth of cut on the surface roughness [13]. Özcatalbas determined that the surface roughness decreased with increased cutting speed but stated that the increase of cutting speed had higher effect in low feed rates; whereas, the effect of cutting speed on surface roughness decreased with increasing feed rate [14]. Aouici et al., investigated experimentally the effect of cutting speed, feed rate, workpiece hardness and depth of cut on surface roughness and cutting force components in hard turning processes. The mathematical model of cutting force and surface roughness components was developed using RSM [15]. Motorcu used the response surface technique to investigate the effects of the cutting speed, feed rate, and depth of cut on surface roughness in turning of AISI 1050 carbon steel. The optimum cutting conditions for the desired surface roughness were defined. The feed rate was determined to be the most effective factor in the experimental results [16]. Makadia and Nanavati examined the effects of turning parameters (feed rate, tool tip radius, cutting speed, and depth of cut) on surface roughness of AISI 410 material. The effect of these parameters on surface roughness was investigated using RSM [17].

In this study, the optimization of the cutting parameters (cutting speed, feed rate and depth of cut) was conducted by using Taguchi $L 27$ Orthogonal array in order to investigate the effect of cutting parameters on the surface roughness in turning process of AISI 409 (ferritic chromium stainless steel) cylindrical material. By using Taguchi method, the cutting parameters giving optimum surface roughness ( $R a$ and $R z$ ) values were determined and the correlation between the parameters was investigated. The most effective parameter was determined for surface roughness. At the end of the present study, the tests were repeated and the deviations between Taguchi estimation and the estimation obtained from repeated tests were calculated.

\section{Material and method}

Experimental study was conducted to determine the effect of three cutting speeds $(200,300$, and $400 \mathrm{~m} / \mathrm{min})$, three feed rates $(0.1,0.2$, and $0.3 \mathrm{~mm} / \mathrm{rev})$ and three depths of cut (1,2, and $3 \mathrm{~mm}$ ) parameters on surface roughness $(R a$ and $R z$ ) in the CNC turning lathe. In the study, AISI 409 material with the dimensions of $\varnothing 60 \times 360 \mathrm{~mm}$ was used. Table 1 shows the chemical composition and mechanical properties of the materials used in the experimental study.

In this study, SPINNER-FANUC T800L brand CNC turning lathe was used. Technical specifications are $4000 \mathrm{rpm}$ spindle, $15 \mathrm{~kW}$ (kilowatts) spindle motor power and $0.001 \mathrm{~mm}$ measurement accuracy. Before conducting 
the experimental study, parameter and axis settings of the lathe were controlled and necessary adjustments were made. Fig. 1 shows the flowchart used for the realization of the experiments.

Table 1

Properties of AISI 409 materials used in the experimental study

\begin{tabular}{|c|c|c|c|c|c|}
\hline $\mathrm{C}(\%)$ & $\mathrm{Si}(\%)$ & $\mathrm{Mn}(\%)$ & $\mathrm{P}(\%)$ & $\mathrm{S}(\%)$ & $\mathrm{Cr}(\%)$ \\
\hline 0.077 & 1.08 & 1.2 & 0.041 & 0.017 & 11.26 \\
\hline \multicolumn{5}{|c|}{ Mechanic Properties } \\
\hline $\begin{array}{c}\text { Elastic Modulus } \\
(\mathrm{GPa})\end{array}$ & $\begin{array}{c}\text { Tensile Strength } \\
(\mathrm{MPa})\end{array}$ & $\begin{array}{c}\text { Yield Strength } \\
0.2 \% \text { Proof } \\
(\mathrm{MPa})\end{array}$ \\
\hline 220 & 470 & 280 \\
\hline
\end{tabular}

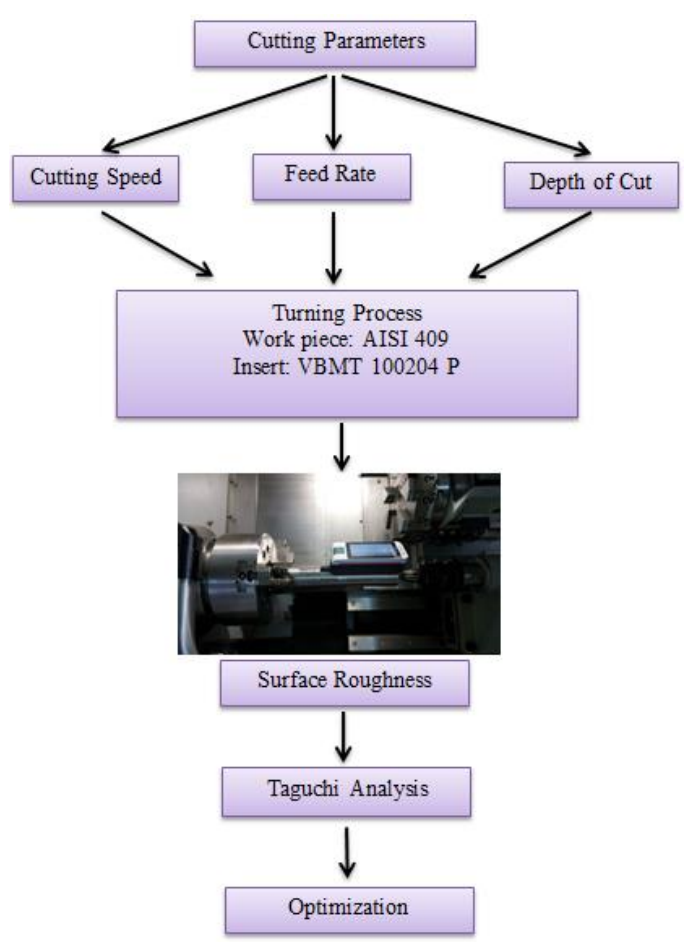

Fig. 1 Experimental design flowchart

In the study, VBMT 100204 P type inserts in IC 907 quality were preferred. Cutting tool catalogue was used to determine the cutting parameters of the tools. Prior to the experiment, a preliminary evaluation opportunity was allowed for the cutting parameters that were used for the cuttings made in the catalogue values. Coolant was not used in the study.

In the experimental study, the effect of independent variables (cutting speed, feed rate, and depth of cut) on the dependent variable (surface roughness) was investigated using Taguchi technique. Table 2 shows the cutting parameters used. The effect sizes of the variables on $R a$ and $R z$ were determined by applying Analysis of Variance (ANOVA) to the experimental results at $95 \%$ confidence interval. Experimental design and statistical analysis conducted according to Taguchi method were performed using Minitab 16 software.

In this study, Taguchi method was used as experimental design and analysis method. A statistical performance measure known as the $S / N$ ratio is used to analyse the experimental results. The results obtained from the experiments are evaluated by converting them into signal-to-noise ratio $(S / N)$. In $S / N$ ratio, $S$ refers to signal factor and $N$ refers to the noise factor. The signal factor refers to the actual value taken from the system and the noise factor refers to the factors that cannot be included in the experimental design but affect the experimental result. In the calculation of $S / N$ ratios, the methods of the nominal is best, the larger is better and the smaller is better are used depending on the characteristic type. Since the surface roughness value was desired to be the smallest in order to determine the $S / N$ values in this study, the formula corresponding to the principle of "the smaller is better" given in Eq. (1) was used [18-21].

$$
\frac{S}{N}=-10 \log \left(\frac{1}{n} \sum_{i=1}^{n} Y i^{2}\right) .
$$

Table 2

A three factor and three level design for experimentation

\begin{tabular}{|c|c|c|c|}
\hline Parameters & Level 1 & Level 2 & Level 3 \\
\hline Cutting speed, $V$ & 200 & 300 & 400 \\
\hline Feed rate, $f$ & 0,1 & 0,2 & 0,3 \\
\hline Depth of cut, $a p$ & 1 & 2 & 3 \\
\hline
\end{tabular}

In order to investigate the effect of cutting parameters on surface roughness ( $R a$ and $R z$ ), Taguchi $L_{27}$ $\left(3^{3}\right)$ experimental setup was prepared (3 trials for each experiment: $27 \times 3=81$ experiments).

RSM is an effective technique in which several input variables may affect some performance criteria or quality characteristics and are useful for finding the most appropriate point for many variables. The purpose of the response surface analysis is to determine the global optimization of the process parameter. The main objective in this technique is to optimize the response surface affected by various process parameters [22].

After the experiments, Mahr MarSurf PS 10 device was used to measure the surface roughness values of the machined surfaces. The cutting length was chosen as 0.8 $\mathrm{mm}$ and the measuring ranges as $4.8 \mathrm{~mm}$ was used to take surface roughness measurements. It was realized by conducting measurements with $10 \mathrm{~mm}$ intervals from three points on the surface of the machined work piece. Values were taken from the highest point of the measurement probe on the piece. The surface roughness values were obtained by taking the arithmetic average of the values after the measurements.

\section{Results and analysis}

In the Taguchi method, $S / N$ ratios and level values were calculated by using the $S / N$ equation of "the smaller is better" in optimum cutting conditions required for the best surface roughness. Table 3 shows the $S / N$ ratios obtained according to the result of this equation. In this study, the correlation between the parameters such as $V, f$ and $a p$ with $R a$ and $R z$ was analysed by the Taguchi orthogonal array. The experimental results and $S / N$ ratios corresponding to $R a$ and $R z$ values were obtained.

Table 3 shows $R a$ and $R z$ values corresponding to $V$, ap, and $f$ values. $S / N$ ratios were compared for each of 27 experiments. The value showing the maximum $S / N$ value shows the most effective parameters in the experimental study. The experimental parameter where the $R a$ and $R z$ surface roughness values were the smallest were determined 
to be the tests conducted with $400 \mathrm{~m} / \mathrm{min} V, 2 \mathrm{~mm} \mathrm{ap}$, and $0.2 \mathrm{~mm} / \mathrm{rev} f$.

The analysis of the effect of each control factor $(V$, $a p, f$ ) on surface roughness was performed with a table called the $S / N$ ratio response table. The response tables of the $S / N$ ratio for $R a$ and $R z$ are shown in Tables 4 and 5, respectively. When Tables 4 and 5 were examined, it was determined that the most effective parameter among the factors was the $f$. It was also observed that the $a p$ and $V$ changes had a significant effect on $R a$ and $R z$.
They show the $S / N$ ratio at each level of the cutting factors and how each cutting factor changes when the settings change from one level to another. The effect of each cutting factor can be predetermined more clearly by response graphs (Fig. 2 and 3, respectively).

When Fig. 2 and Fig. 3 were examined, it was seen that level 3 of the $V$, level 2 of the ap and level 2 of the $f$ were the effective parameters for surface roughness in the experimental study. The optimal cutting parameters for $R a$ and $R z$ surface roughness were $V_{3} a p_{2} f_{2}\left(V_{3}=400 \mathrm{~m} / \mathrm{min}\right.$, $\left.a p_{2}=2 \mathrm{~mm}, f_{2}=0,2 \mathrm{~mm} / \mathrm{rev}\right)$.

Table 3

$L 27\left(3^{3}\right)$ orthogonal array, experimental results and their $S / N$ ratios

\begin{tabular}{|c|c|c|c|c|c|c|c|}
\hline \multirow{2}{*}{ Trial Number } & \multicolumn{3}{|c|}{ Main Cutting Parameters } & \multicolumn{2}{|c|}{ Measured Surface Roughness Values } & \multicolumn{2}{|c|}{$S / N$ Ratio } \\
\hline & $V(\mathrm{~m} / \mathrm{min})$ & $a p(\mathrm{~mm})$ & $f(\mathrm{~mm} / \mathrm{rev})$ & $R a(\mu \mathrm{m})$ & $R z(\mu \mathrm{m})$ & $R a(\mathrm{~dB})$ & $R z(\mathrm{~dB})$ \\
\hline 1 & 200 & 1 & 0,1 & 1,884 & 10,791 & $-5,500$ & $-20,661$ \\
\hline 2 & 300 & 1 & 0,1 & 1,754 & 8,578 & $-4,881$ & $-18,668$ \\
\hline 3 & 400 & 1 & 0,1 & 1,603 & 8,993 & $-4,099$ & $-19,078$ \\
\hline 4 & 200 & 1 & 0,2 & 4,253 & 17,613 & $-12,574$ & $-24,917$ \\
\hline 5 & 300 & 1 & 0,2 & 4,096 & 18,130 & $-12,247$ & $-25,168$ \\
\hline 6 & 400 & 1 & 0,2 & 4,061 & 17,630 & $-12,172$ & $-24,925$ \\
\hline 7 & 200 & 1 & 0,3 & 8,946 & 39,564 & $-19,033$ & $-31,946$ \\
\hline 8 & 300 & 1 & 0,3 & 8,805 & 38,987 & $-18,894$ & $-31,818$ \\
\hline 9 & 400 & 1 & 0,3 & 8,953 & 41,196 & $-19,040$ & $-32,297$ \\
\hline 10 & 200 & 2 & 0,1 & 3,456 & 18,028 & $-12,979$ & $-26,033$ \\
\hline 11 & 300 & 2 & 0,1 & 6,459 & 29,036 & $-14,742$ & $-28,312$ \\
\hline 12 & 400 & 2 & 0,1 & 4,161 & 18,820 & $-12,385$ & $-25,493$ \\
\hline 13 & 200 & 2 & 0,2 & 1,800 & 10,341 & $-5,104$ & $-19,408$ \\
\hline 14 & 300 & 2 & 0,2 & 1,692 & 10,006 & $-4,566$ & $-20,005$ \\
\hline 15 & 400 & 2 & 0,2 & 1,370 & 7,332 & $-2,732$ & $-17,304$ \\
\hline 16 & 200 & 2 & 0,3 & 3,943 & 17,413 & $-11,917$ & $-24,304$ \\
\hline 17 & 300 & 2 & 0,3 & 3,451 & 15,507 & $-10,758$ & $-23,810$ \\
\hline 18 & 400 & 2 & 0,3 & 3,511 & 16,052 & $-10,908$ & $-24,111$ \\
\hline 19 & 200 & 3 & 0,1 & 7,499 & 34,727 & $-16,257$ & $-30,029$ \\
\hline 20 & 300 & 3 & 0,1 & 4,027 & 20,176 & $-12,100$ & $-26,517$ \\
\hline 21 & 400 & 3 & 0,1 & 4,081 & 19,359 & $-12,216$ & $-25,738$ \\
\hline 22 & 200 & 3 & 0,2 & 2,400 & 14,817 & $-7,604$ & $-23,982$ \\
\hline 23 & 300 & 3 & 0,2 & 1,830 & 11,162 & $-5,247$ & $-20,955$ \\
\hline 24 & 400 & 3 & 0,2 & 1,784 & 11,086 & $-5,026$ & $-20,895$ \\
\hline 25 & 200 & 3 & 0,3 & 3,502 & 17,192 & $-10,886$ & $-25,198$ \\
\hline 26 & 300 & 3 & 0,3 & 3,218 & 15,416 & $-10,152$ & $-23,759$ \\
\hline 27 & 400 & 3 & 0,3 & 3,143 & 14,779 & $-9,946$ & $-23,393$ \\
\hline
\end{tabular}

Table 4 the $R a$ value decreased as the $V$ increased in parallel with

Response Table for $S / N$ Ratios for $R a$

\begin{tabular}{|c|c|c|c|c|c|}
\hline Factors & Level 1 & Level 2 & Level 3 & Delta $(\delta)$ & Rank \\
\hline$V$ & $-11,31$ & $-10,39$ & $\mathbf{- 9 , 8 3}$ & 1,48 & 3 \\
\hline$a p$ & $-12,04$ & $\mathbf{- 9 , 5 6}$ & $-9,93$ & 2,48 & 2 \\
\hline$f$ & $-10,57$ & $\mathbf{- 7 , 4 7}$ & $-13,50$ & 6,02 & 1 \\
\hline
\end{tabular}

Table 5

Response Table for $S / N$ Ratios for $R z$

\begin{tabular}{|c|c|c|c|c|c|}
\hline Factors & Level 1 & Level 2 & Level 3 & Delta $(\delta)$ & Rank \\
\hline$V$ & $-25,16$ & $-24,03$ & $\mathbf{- 2 3 , 6 9}$ & 1,47 & 3 \\
\hline$a p$ & $-25,50$ & $\mathbf{- 2 3 , 2 0}$ & $-24,50$ & 2,3 & 2 \\
\hline$f$ & $-24,50$ & $\mathbf{- 2 1 , 9 5}$ & $-26,74$ & 4,79 & 1 \\
\hline
\end{tabular}

The effect of cutting parameters on surface roughness $(R a)$ is given in $3 \mathrm{D}$ surface graphs in Fig. 4. It showed the effect of $V$ - $f, V$-ap and $f$-ap cutting parameters on $R a$. When Fig. 4, a was examined, it was determined that the literature. Fig. 4, b shows the effect of the $V$ and $a p$ on the $R a$. It was seen that the $R a$ value decreased as the $a p$ increased. When the correlation between the $f$ and $a p$ in Fig. 4, c was examined, it was determined that as the $f$ increased, $R a$ value increased; whereas, as the ap increases, the $R a$ value decreased.

Therefore, it was determined that there was a direct correlation between $R a$ and $f$. This result supports the evaluation made according to $S / N$ ratios and is in parallel with the theoretical formula $\left(R a=0.321 f^{2} / R\right)$ pointing out that the surface roughness value will increase proportionally with the square of $f$.

The $R a$ value decreased with increasing $a p$. It is not usually seen in the literature. The reason for this is that as the $a p$ increases, the heat caused by friction between the tool and the workpiece will increase and the temperature of the material will increase. Therefore, it is thought that the tool will be able to remove chips from the heated material and $R a$ value will decrease. 


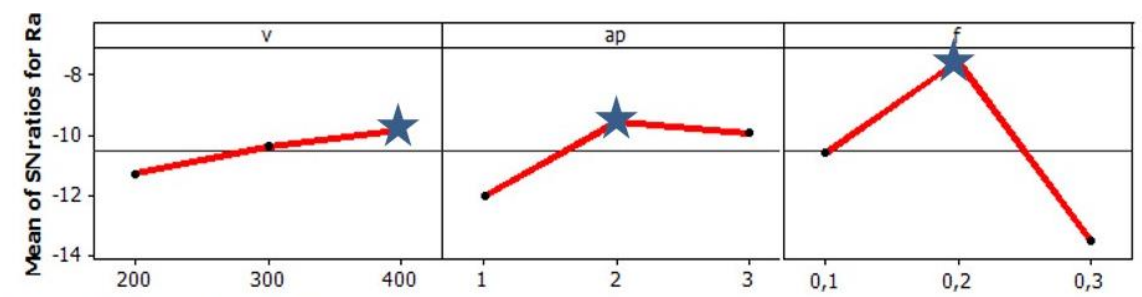

Signal-to-noise: Smaller is better

Fig. 2 Main Effects Plot for $S / N$ ratios for $R a$

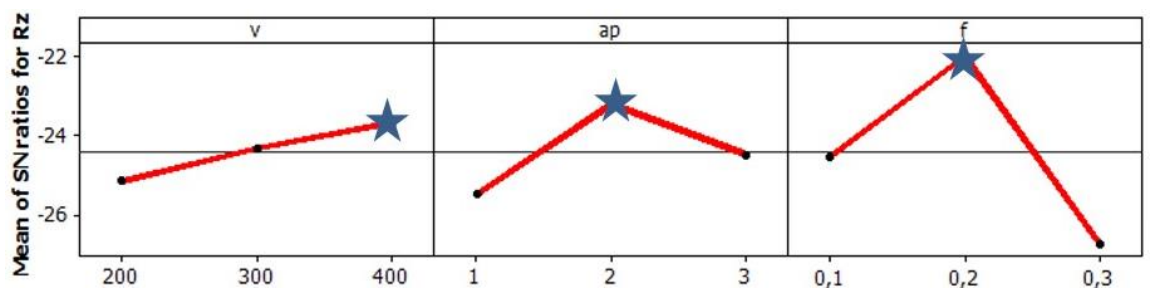

Fig. 3 Main Effects Plot for $S / N$ ratios for $R z$

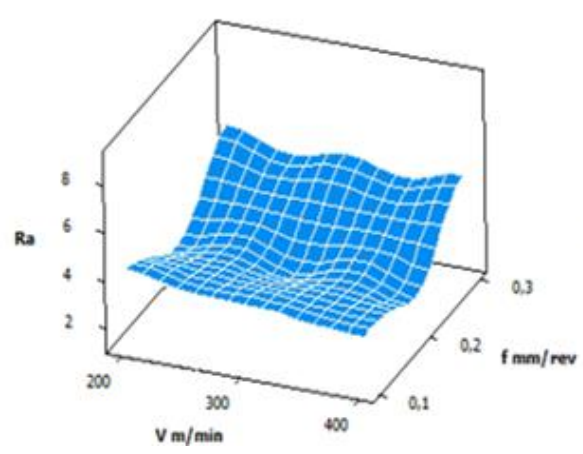

a

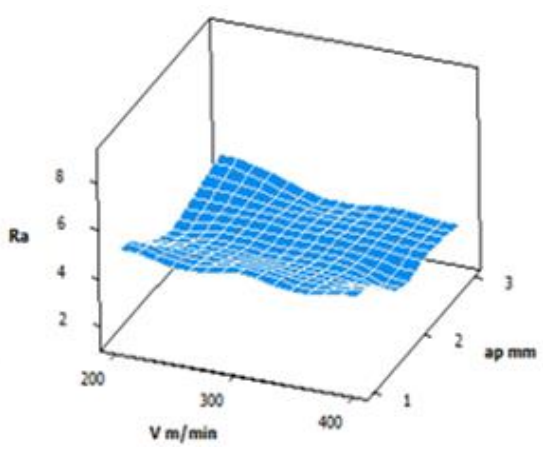

b

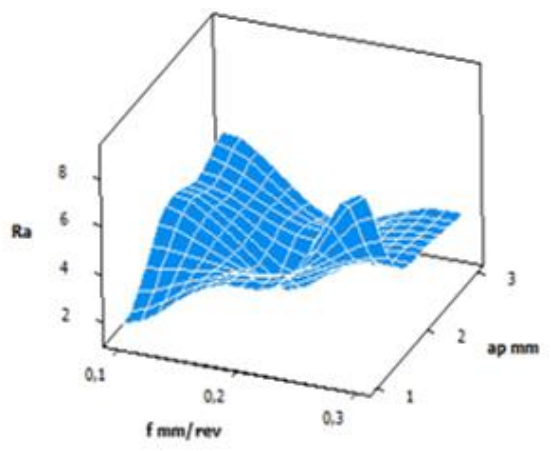

c

Fig. $4 R a$ effects of the experimental parameters and 3D surface graphs ( $a=V-f ; b=V$-ap; $c=f-a p)$

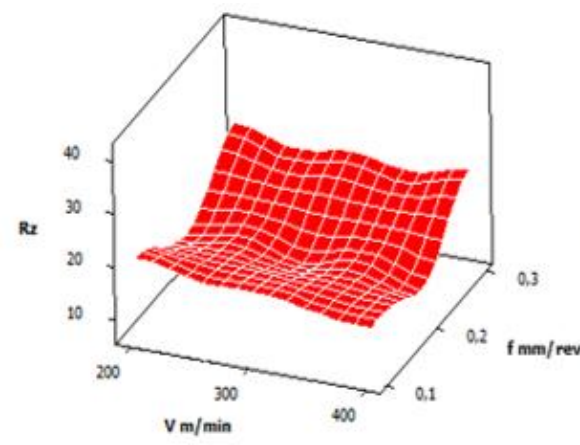

a

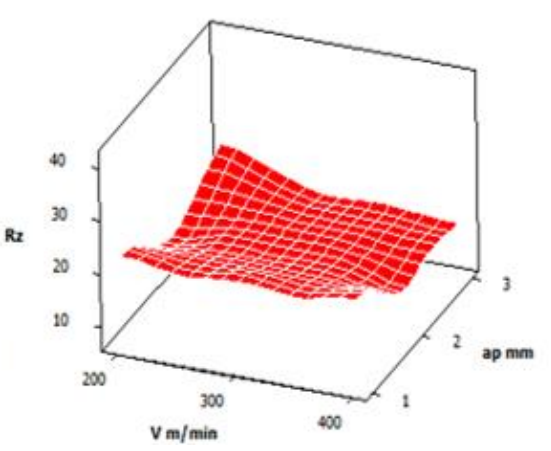

b

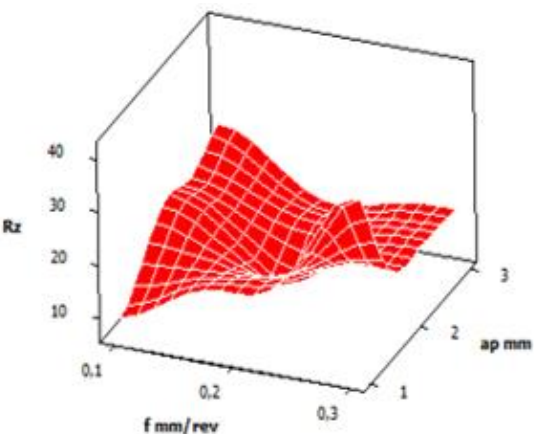

C

Fig. $5 R z$ effects of the experimental parameters and 3D surface graphs $(a=V-f ; b=V$-ap; $c=f-a p)$

It was reported that the permanent stresses forming during the machining of the steel had a significant effect on $R a$. It is known that the temperature in the cutting zone increases as the $f$ increases and the resulting heat is concentrated on the tool-chip and tool work piece interface due to the low thermal conductivity of the stainless steel [23-25]. In this context, it is an expected result that as the $f$ increases, permanent stresses on the machined surface increase and there is an increase in $R a$ values.

Fig. 5 shows the effect of $V, f$ and $a p$ on $R z$. Fig. 5, a shows the effect of $V$ and $f$, Fig. 5, b shows the $V$ and $a p$ and Fig. 5, c shows the correlation between the $f$ and $a p$. The surface roughness $(R z)$ decreases as $V$ and $a p$ increase and it tends to increase as $f$ increases.
The contour plot shown in Fig. 6 shows the correlation between the depth of cut and the cutting speed. The light regions in the plot indicated that the surface roughness deteriorated due to the cutting conditions and the dark regions show that the $R a$ improved. Using the plot, the most suitable cutting parameters for $R a$ can be determined.

It was observed that the best $R a$ value was below $<2 \mu \mathrm{m}$ in $300 \mathrm{~m} / \mathrm{min}$ and $400 \mathrm{~m} / \mathrm{min} V$ and between $2 \mathrm{~mm}$ and $3 \mathrm{~mm}$ ap. It was understood from the Figure that the maximum $R a$ was between 4-5 $\mu \mathrm{m}$ in the range of $1 \mathrm{~mm}$ and $1.4 \mathrm{~mm}$ ap and in increasing $V$. The contour plot in Fig. 6, b shows the effect of the $V$ and $f$ parameters on the $R a$. The dark coloured parts on the figure show the region where the $R a$ value was the best $(<2 \mu \mathrm{m})$ and green coloured areas show the parts with the highest surface roughness $(5-6 \mu \mathrm{m})$. 
When the correlation between the $a p$ and $f$ in Fig. 6, c was examined, it was observed that the $R a$ values were the lowest $(<2 \mu \mathrm{m})$ in the regions cut with $0.16 \mathrm{~mm} / \mathrm{rev}$ and $0.27 \mathrm{~mm} / \mathrm{rev} f$ and $1.7 \mathrm{~mm}$ and $3 \mathrm{~mm}$ ap. On the other hand, the $R a$ values were the highest in the $0.22 \mathrm{~mm} / \mathrm{rev} f$ and $1.5 \mathrm{~mm}$ ap.

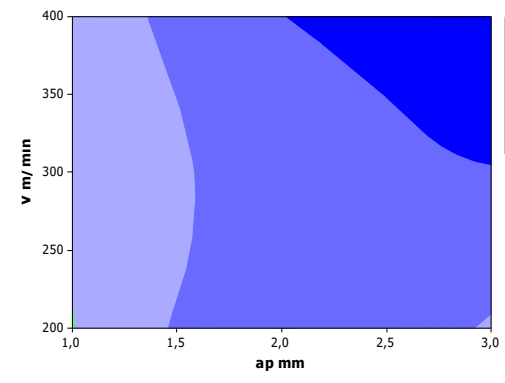

a
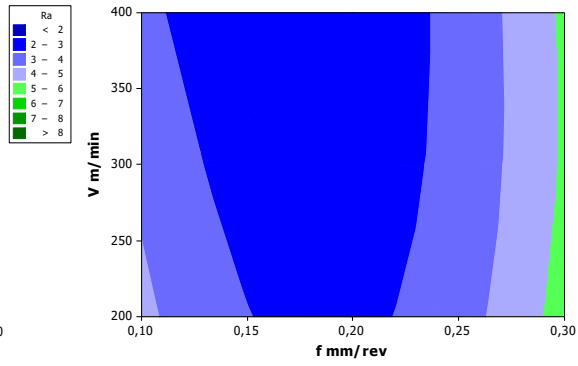

b
Fig. 7 shows contour plot showing the effect of $V$, $f$ and $a p$ on surface roughness $(R z)$. In the figure, the dark coloured areas show the region where $R z$ is the lowest and the light coloured areas show the region where $R z$ is higher.

Fig. $6 R a$ effects of the experimental parameters and 2D contour graphs $(a=V-a p ; b=V-f ; c=a p-f)$

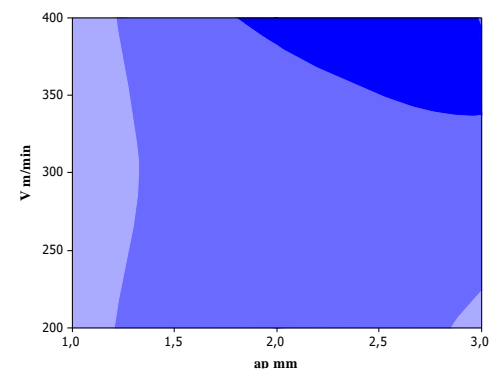

a
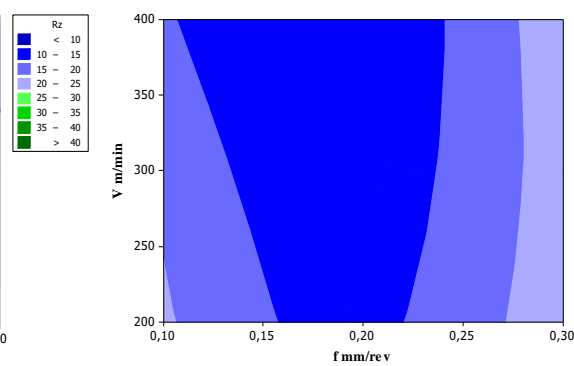

b
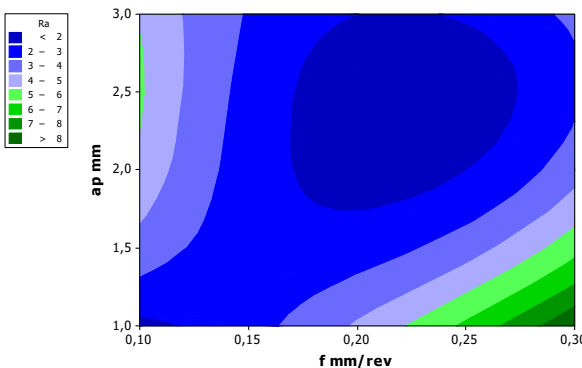

c
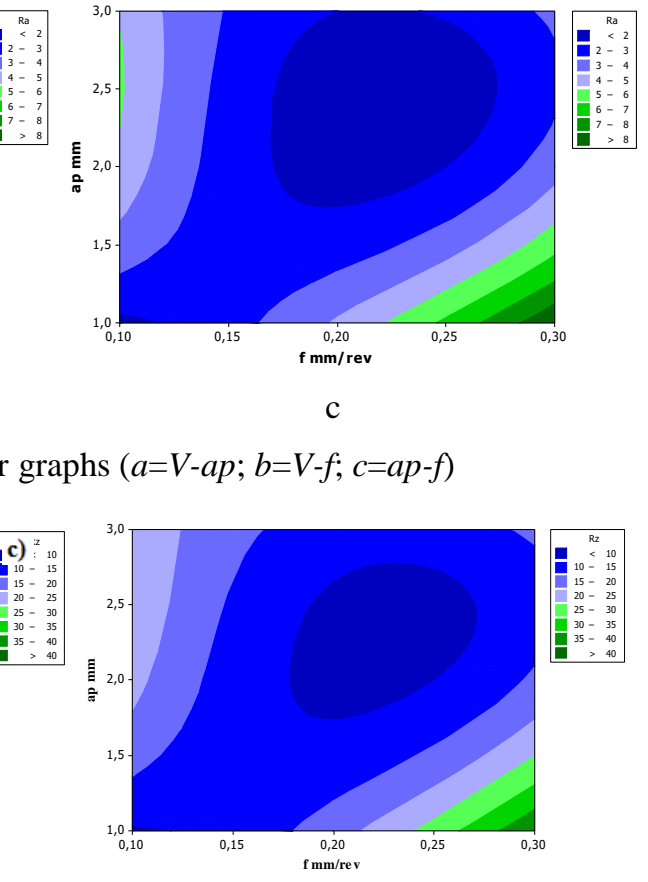

$\mathrm{c}$

Fig. $7 R z$ effects of the experimental parameters and 2D contour graphs ( $a=V-a p ; b=V-f ; c=a p-f)$

Analysis of variance for $S / N$ ratios for $R a$

Table 6

\begin{tabular}{|c|c|c|c|c|c|c|c|}
\hline Source & $D F$ & Seq. SS & Adj. SS & Adj. MS & $F$ & $p$ & Contribution (\%) \\
\hline$V$ & 2 & 10,062 & 10,062 & 5,0311 & 7,04 & 0,017 & 1,72 \\
\hline$a p$ & 2 & 32,289 & 32,289 & 16,1446 & 22,58 & 0,001 & 5,53 \\
\hline$f$ & 2 & 163,603 & 163,603 & 81,8015 & 114,39 & 0,000 & 28,03 \\
\hline$V^{*} a p$ & 4 & 6,253 & 6,253 & 1,5633 & 2,19 & 0,161 & 1,07 \\
\hline$V^{*} f$ & 4 & 1,729 & 1,729 & 0,4324 & 0,6 & 0,670 & 0,30 \\
\hline$a p * f$ & 4 & 363,991 & 363,991 & 90,9976 & 127,25 & 0,000 & 62,36 \\
\hline Residual Error & 8 & 5,721 & 5,721 & 0,7151 & & & 0,98 \\
\hline Total & 26 & 583,648 & & & & & 100 \\
\hline
\end{tabular}

Table 7

Analysis of variance for $S / N$ ratios for $R z$

\begin{tabular}{|c|c|c|c|c|c|c|c|}
\hline Source & $D F$ & Seq. SS & $A d j . S S$ & Adj. MS & $F$ & $p$ & Contribution (\%) \\
\hline$V$ & 2 & 9,797 & 9,797 & 4,8983 & 7,27 & 0,016 & 2,28 \\
\hline$a p$ & 2 & 23,938 & 23,938 & 11,9688 & 17,77 & 0,001 & 5,58 \\
\hline$f$ & 2 & 103,244 & 103,244 & 51,6218 & 76,65 & 0,000 & 24,06 \\
\hline$V^{*} a p$ & 4 & 11,959 & 11,959 & 2,9897 & 4,44 & 0,035 & 2,79 \\
\hline$V^{*} f$ & 4 & 2,367 & 2,367 & 0,5917 & 0,88 & 0,518 & 0,55 \\
\hline$a p * f$ & 4 & 272,471 & 272,471 & 68,1178 & 101,14 & 0,000 & 63,49 \\
\hline Residual Error & 8 & 5,388 & 5,388 & 0,6735 & & & 1,26 \\
\hline Total & 26 & 429,162 & & & & & 100 \\
\hline
\end{tabular}

Tables 6 and 7 show the analysis of variance (ANOVA) values of the $S / N$ ratios of the surface roughness values $(R a$ and $R z)$. When Table 6 was examined, it was determined that $V$, ap and $f$ values were significant in terms of $p$ significance value $(p<0.05)$. From $V, a p$ and $f$ interactions, $V^{*} a p$ and $a p * f$ were significant in terms of $p<0.05$ value, $V * f$ interaction was insignificant due to $p<0.05$ value. The highest contribution of $V$, ap, and $f$ cutting parameters for $R a$ value was found to be the $f$ with the value of $28.03 \%$. It was determined that the $a p$ and $V$ parameters contributed by $5.53 \%$ and $1.72 \%$, respectively. It was also observed that among the independent variables, 
the interaction between $a p$ and $f$ was effective by $62.36 \%, V$ and $a p$ were effective by $1.07 \%$ and $f$ was effective by $0.30 \%$.

When Table 7 is examined, the most contribution among the cutting parameters was seen to be $f$ by the rate of $24.06 \%$. When the interactions between the parameters were examined, it was determined that $a p * f$ interaction was effective by $63.49 \%$. In terms of $F$ value, it was determined that $f$ value was 76.65 and $a p * f$ interaction was 101.14 . In terms of $p$ significance value $(p<0.05)$, it was found that $V^{* f}$ interaction was not significant, other parameters $(V, a p$, and $f$ ) and their interactions ( $V^{*} a p$ and $\left.a p^{*} f\right)$ were significant.

Figs. 8 and 9 shows residual graphs of the model developed for cutting parameters in turning operation in order to check adequacy. When the distributions were normal, the normal plot of residual gave residual values versus their expected values. The normal graph of the remaining residues showed that the data complied with the sample size rules and confidence intervals on the straight line, and that the $p$ values were correct. Ideally for the remaining and installed plots, all points should fall randomly on both sides of the zero as in the recognizable pattern. Figs. 8 and 9 clearly show that all points are placed on both sides of zero and no unstable variance or contradiction is observed $[22,23]$. He confirmed that the residues were randomly distributed with constant variances. The order versus residue graph showed the order in which the data was collected and the patterns during the observation and at the points. Ideally, the residue remaining
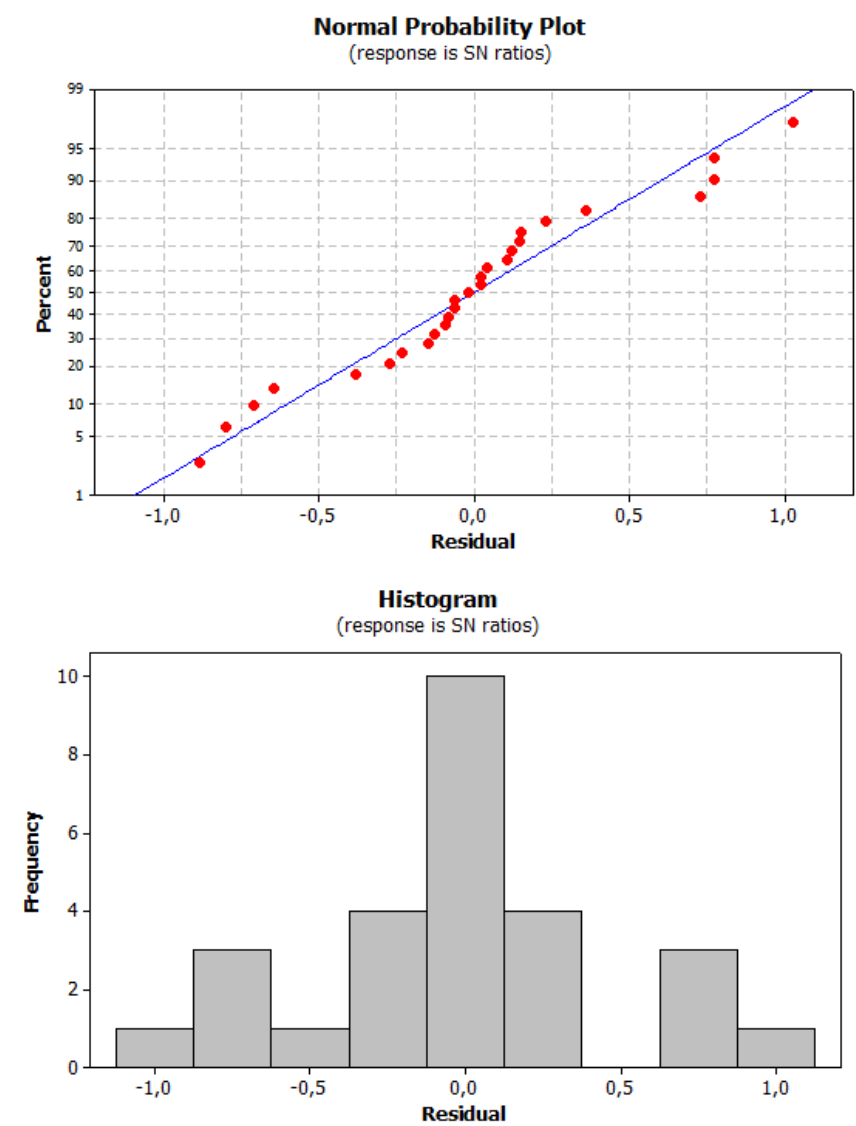

on the plot should fall randomly around the center line. Fig. 8 and 9 clearly show that residues close to each other are correlated and therefore not independent. Fig. 10 show the comparative plot of the results of the simulation surface roughness ( $R a$ and $R z$ ) obtained by the Taguchi technique and the experimental results. When the figure was examined, the experimental and simulation results were observed to be compatible with each other.

The relationship between surface roughness and machining parameters such as $V, f$, and ap for the second order response surface model was developed using RSM from the data observed in uncoded units as follows. The predicted actual uncoded factors, i.e., $R a$ and $R z$ was calculated using Eqs. (2) and (3) and plotted in Fig. 10. The maximum error for $R a$ and $R z$ of $12.082 \%$ and $11.891 \%$ of surface roughness was observed between the simulated and experimental results respectively are tabulated in Table 8 .

$$
\begin{aligned}
& R a=5,69114-0,00721630 * V+0,961611 * a p- \\
& -31,7101 * f+9,36 * 10^{-6}+0,841963 * a p^{2}+ \\
& +193,485 * f^{2}-0,00244 * V * a p+ \\
& +0,0184083 * v * f-21,8403 * a p * f . \\
& R z=23,8334-0,0173761 * V+3,89643 * a p- \\
& -135,946 * f+2,63 * 10^{-5}+4,50704 * a p^{2}+ \\
& +807,681 * f^{2}-0,0169689 * V * a p+ \\
& +0,110278 * v^{*} f-96,0497 * a p * f .
\end{aligned}
$$
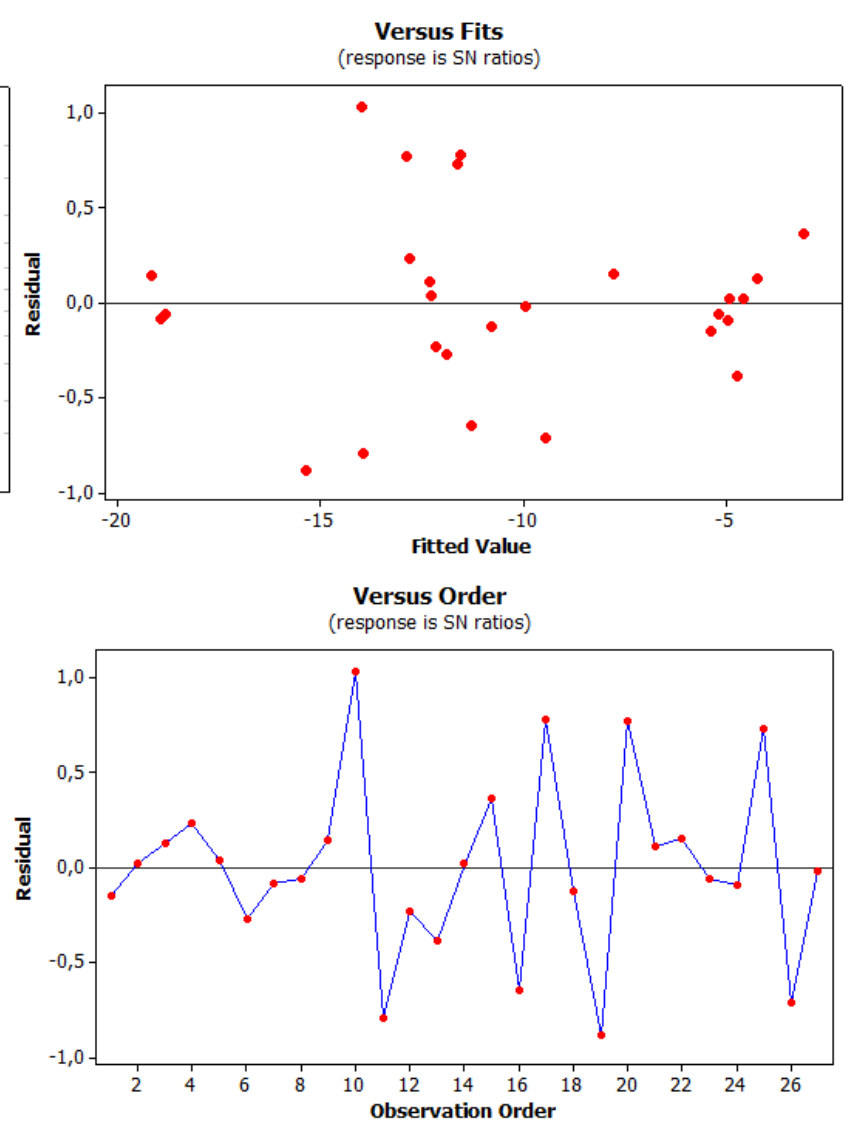

Fig. 8 Residual plots of model for $R a$

Using Taguchi optimization method, the optimum results of $R a$ and $R z$ values were obtained in the experimental study and the percentage distributions of the parameters affecting the result were determined by ANOVA analysis. The final step of the optimization process is carrying out the validation tests and testing the validation of 
the optimization process. As a result of the Taguchi optimization, while the parameter group giving the optimal surface roughness value could be any of the existing tests, sometimes it may be a test other than the experimental tests. In the study, the optimal result for the surface roughness was obtained in $V_{2} a p_{2} f_{2}$ experimental conditions from the current
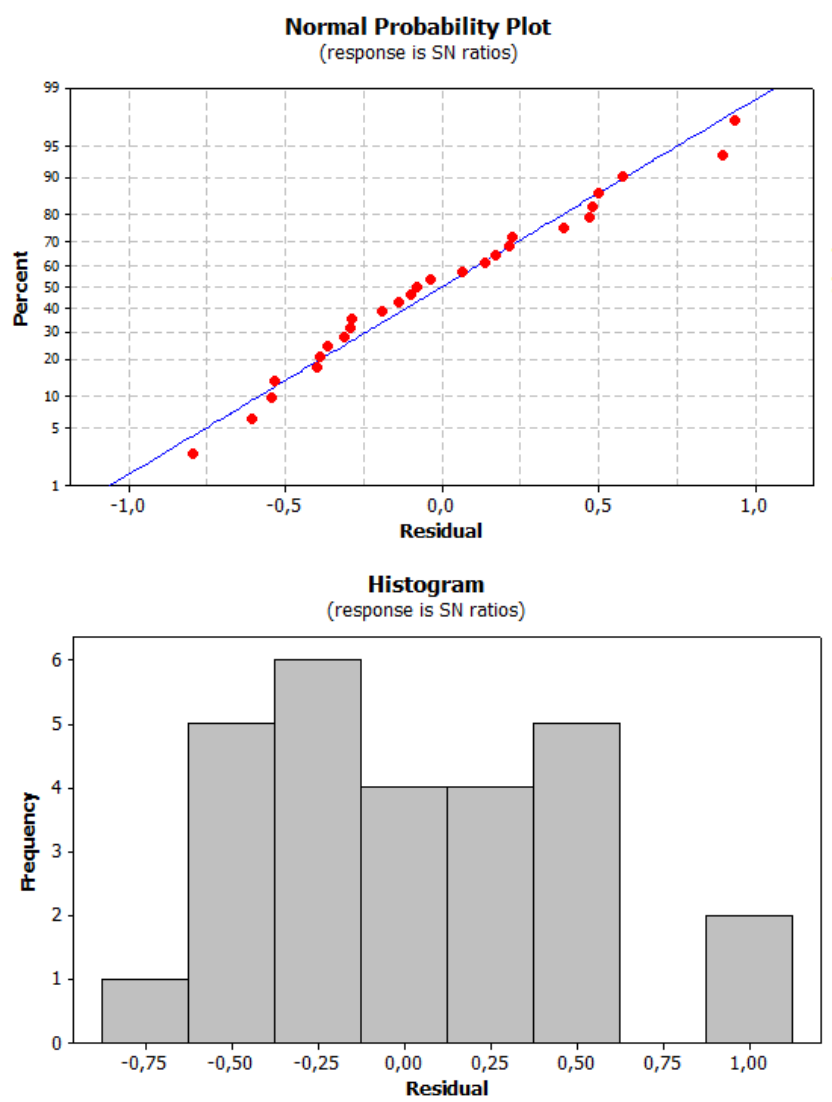

tests. When the $R a$ and $R z$ values in Table 9 were compared, it was observed that high convergence values of $\mathrm{Ra} 86.18 \%$ and $R z$ 99.37\% were obtained. In this context, it is noteworthy that the difference between the results obtained from the Taguchi approach and the validation test results is negligible.
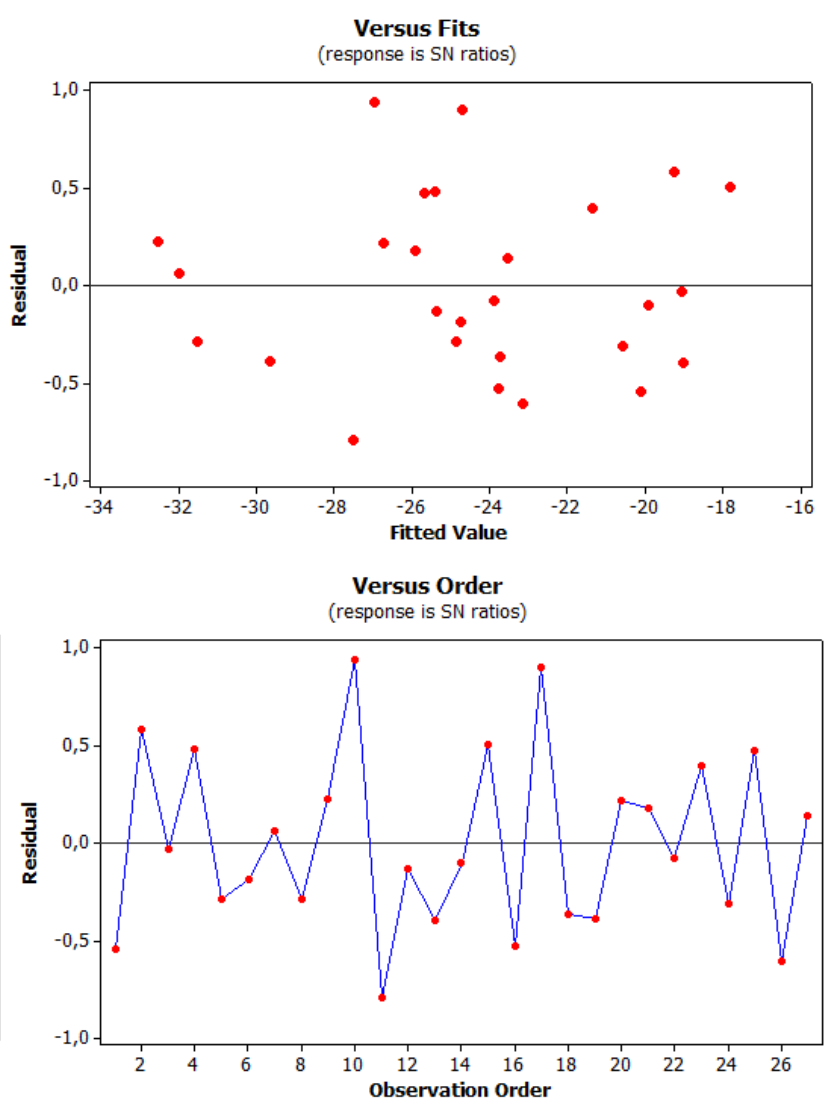

Fig. 9 Residual plots of model for $R z$

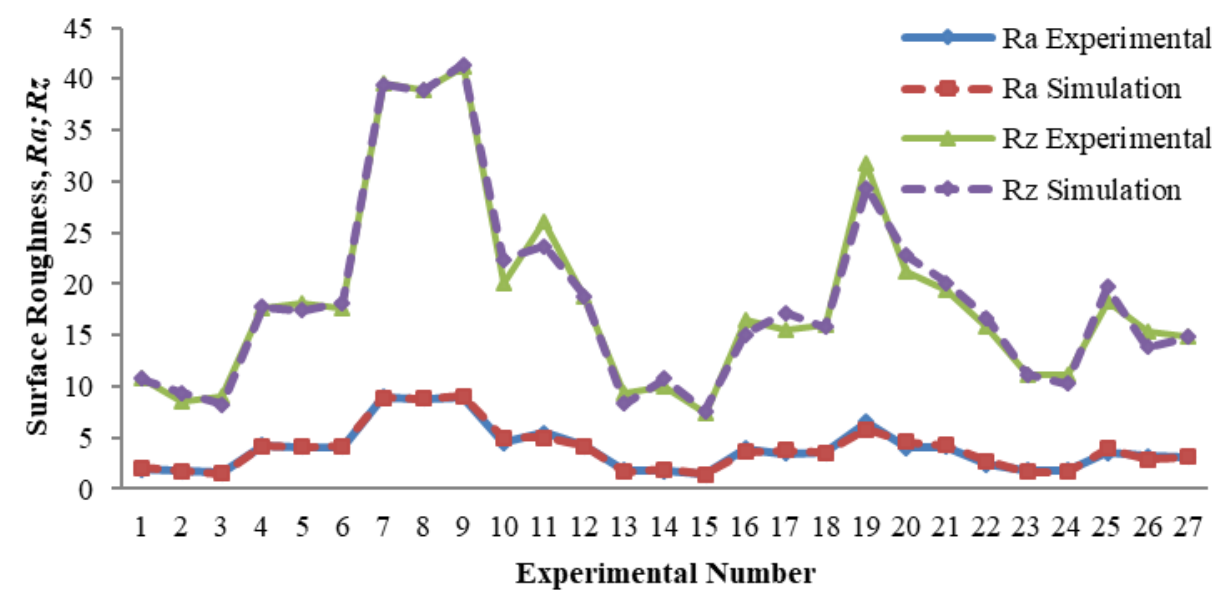

Fig. 10 Comparison of experimental and estimated results for $R a$ and $R z$

Table 8

Error \% between predicted and measured surface roughness ( $R a$ and $R z$ )

\begin{tabular}{|c|c|c|c|c|c|c|}
\hline Trial Number & Measured $R a(\mu \mathrm{m})$ & Prediction $R a(\mu \mathrm{m})$ & $\%$ Error & Measured $R z(\mu \mathrm{m})$ & Prediction $R z(\mu \mathrm{m})$ & $\%$ Error \\
\hline 1 & 1,884 & 2,047 & $-7,958$ & 10,791 & 10,748 & 0,402 \\
\hline 2 & 1,754 & 1,743 & 0,618 & 8,578 & 9,348 & $-8,233$ \\
\hline 3 & 1,603 & 1,451 & 10,483 & 8,993 & 8,266 & 8,787 \\
\hline 4 & 4,253 & 4,156 & 2,325 & 17,613 & 17,759 & $-0,819$ \\
\hline 5 & 4,096 & 4,108 & $-0,285$ & 18,130 & 17,453 & 3,877 \\
\hline 6 & 4,061 & 4,146 & $-2,049$ & 17,630 & 18,161 & $-2,925$ \\
\hline 7 & 8,946 & 8,880 & 0,746 & 39,564 & 39,462 & 0,259 \\
\hline
\end{tabular}




\begin{tabular}{|c|c|c|c|c|c|c|}
\hline Trial Number & Measured $R a(\mu \mathrm{m})$ & Prediction $R a(\mu \mathrm{m})$ & $\%$ Error & Measured $R z(\mu \mathrm{m})$ & Prediction $R z(\mu \mathrm{m})$ & $\%$ Error \\
\hline 8 & 8,805 & 8,804 & 0,011 & 38,987 & 38,894 & 0,239 \\
\hline 9 & 8,953 & 9,020 & $-0,745$ & 41,196 & 41,391 & $-0,471$ \\
\hline 10 & 3,456 & 4,976 & $-10,454$ & 18,028 & 22,409 & $-10,627$ \\
\hline 11 & 6,459 & 4,950 & 10,283 & 29,036 & 23,690 & 9,905 \\
\hline 12 & 4,161 & 4,150 & 0,270 & 18,820 & 18,786 & 0,185 \\
\hline 13 & 1,800 & 1,625 & 10,771 & 10,341 & 8,348 & 11,891 \\
\hline 14 & 1,692 & 1,853 & $-8,698$ & 10,006 & 10,722 & $-6,684$ \\
\hline 15 & 1,370 & 1,383 & $-0,999$ & 7,332 & 7,608 & $-3,628$ \\
\hline 16 & 3,943 & 3,598 & 9,595 & 17,413 & 15,024 & 9,243 \\
\hline 17 & 3,451 & 3,798 & $-9,157$ & 15,507 & 17,137 & $-9,511$ \\
\hline 18 & 3,511 & 3,508 & 0,075 & 16,052 & 15,811 & 1,525 \\
\hline 19 & 7,499 & 5,816 & 11,744 & 34,727 & 29,389 & 7,956 \\
\hline 20 & 4,027 & 4,547 & $-11,431$ & 20,176 & 22,753 & $-6,931$ \\
\hline 21 & 4,081 & 4,245 & $-3,847$ & 19,359 & 20,120 & $-3,783$ \\
\hline 22 & 2,400 & 2,672 & $-10,168$ & 14,817 & 16,664 & $-5,084$ \\
\hline 23 & 1,830 & 1,657 & 10,434 & 11,162 & 11,122 & 0,359 \\
\hline 24 & 1,784 & 1,685 & 5,862 & 11,086 & 10,279 & 7,853 \\
\hline 25 & 3,502 & 3,913 & $-10,513$ & 17,192 & 19,683 & $-7,575$ \\
\hline 26 & 3,218 & 2,871 & 12,082 & 15,416 & 13,879 & 11,074 \\
\hline 27 & 3,143 & 3,078 & 2,097 & 14,779 & 14,825 & $-0,311$ \\
\hline
\end{tabular}

Table 9

Comparison of the prediction model and experimental results

\begin{tabular}{|c|c|c|c|c|c|}
\hline Parameters & Parameters levels & \multicolumn{2}{|c|}{ Values of $R a(\mu \mathrm{m})$} & \multicolumn{2}{|c|}{ Values of $R z(\mu \mathrm{m})$} \\
\hline$V(\mathrm{~m} / \mathrm{min})$ & 300 & Prediction & Experimental & Prediction & Experimental \\
\hline$f(\mathrm{~mm} / \mathrm{rev})$ & 0,2 & 1,9633 & 1,6920 & 9,9438 & 10,0060 \\
\hline$a p(\mathrm{~mm})$ & 2 & & & \\
\hline
\end{tabular}

\section{Conclusion}

In this study, $R a$ and $R z$ values were analysed in terms of cutting parameters using Taguchi experimental design for the optimization of turning process. The results obtained in the study were given below.

- According to the variance analysis of $S / N$ ratios, the importance order of the variables affecting the $R a$ and $R z$ was determined as $f$, $a p$ and $V$, respectively.

- It was observed that the $R a$ and $R z$ value of the work piece increased as the $f$ increased. It showed a decreasing trend with increasing $V$. Better surface quality was obtained at low $f$. This is compatible with the studies in the literature.

- Optimum machining parameters giving the lowest surface roughness $(R a=1.370 \mu \mathrm{m}$ and $R z=7.332$ $\mu \mathrm{m})$ values in the optimization conducted with the help of $S / N$ analysis were found to be $400 \mathrm{~m} / \mathrm{min}$ $V, 2 \mathrm{~mm}$ ap and $0.2 \mathrm{~mm} / \mathrm{rev} f$.

- The prediction models deduced for the components of the surface roughness are in very good agreement with values obtained experimentally.

- As a result of validation tests, high convergence values of $R a(86.18 \%)$ and $R z(99.37 \%)$ were determined.

- It was determined according to ANOVA results that the most effective parameter on the surface roughness was $f$; whereas, the interaction of $a p$ and $f$ had a high contribution to the experimental results.

\section{References}

1. Neşeli, S.; Yaldız, S. 2007. The effects of approach angle and rake angle due to chatter vibrations on surface roughness in turning, Journal of Polytechnic 10: 383389.

http://doi.org/10.2339/2007.10.4.383-389.

2. Nalbant, M.; Gökkaya, H.; Sur, G. 2007. Application of Taguchi method in the optimization of cutting parameters for surface roughness in turning, Mater. Des., 28: 1379-1385.

http://doi.org/10.1016/j.matdes.2006.01.008.

3. Günay, M. 2013. Optimization with Taguchi method of cutting parameters and tool nose radius in machining of AISI 316L steel, Journal of the Faculty of Engineering and Architecture of Gazi University 28: 437-444.

4. Çakir, M. C.; Ensarioglu, C.; Demirayak, I. 2009. Mathematical modeling of surface roughness for evaluating the effects of cutting parameters and coating material, Journal of Materials Processing Technology 209:102-109. http://doi.org/10.1016/j.jmatprotec.2008.01.050.

5. Yang, A.; Han, Y.; Pan, Y.; Xing, H.; Li, J. 2017. Optimum surface roughness prediction for titanium alloy by adopting response surface methodology, Results in Physics 7: 1046-1050.

https://doi.org/10.1016/j.rinp.2017.02.027.

6. Selvaraj, D. P. 2018. Optimization of surface roughness of duplex stainless steel in dry turning operation using Taguchi technique, Materials Physics and Mechanics 40: 63-70.

http://doi.org/10.18720/MPM.4012018_8, 
7. Yan, H.; Hua, J.; Shivpuri, R. 2005. Numerical simulation of finish hard turning for AISI H13 Die Steel, Science and Technology of Advanced Materials 6: 540-547. http://doi.org/10.1016/j.stam.2005.04.002.

8. Yücel, E. and Günay, M. 2013. Modelling and optimization of the cutting conditions in hard turning of highalloy white cast iron (Ni-Hard), Proceedings of the Institution of Mechanical Engineers, Part C: Journal of Mechanical Engineering Science, 10: 2280-2290. https://doi.org/10.1177/0954406212471755.

9. Sahoo, A. K. 2014. Application of Taguchi and regression analysis on surface roughness in machining hardened AISI D2 steel, International Journal of Industrial Engineering Computations 5: 295-304. https://doi.org/10.5267/j.ijiec.2013.11.001.

10. Bouacha, K.; Yallese, M. A.; Mabrouki, T.; Rigal, J. F. 2010. Statistical analysis of surface roughness and cutting forces using response surface methodology in hard turning of AISI 52100 bearing steel with CBN tool, International Journal of Refractory Metals and Hard Materials 28: $349-361$. https://doi.org/10.1016/j.ijrmhm.2009.11.011.

11. Özlü, B.; Demir, H.; Nas, E. 2014. The mathematical modeling of parameters effecting surface roughness and cutting force during cnc turning process, Journal of Advanced Technology Sciences 3: 75-86.

12. Fnides, B.; Yallese, M. A.; Mabrouki, T.; Rigal, J. F. 2009. Surface roughness model in turning hardened hot work steel using mixed ceramic tool, Mechanika 3: 6873. https://doi.org/10.1007/s12046-011-0007-7.

13. Bouzid, L.; Yallese, M. A.; Belhadi, S. 2014. RMSbased optimisation of surface roughness when turning AISI 420 stainless steel, International Journal of Materials and Product Technology 49: 224-251. https://doi.org/10.1504/IJMPT.2014.064934.

14. Özçatalbas, Y.; Ercan, F. 2003. The effects of heat treatment on the machinability of mild steels, Journal of Materials Processing Technology 136: 227-238. https://doi.org/10.1016/S0924-0136(03)00273-5.

15. Aouici, H.; Yallese, M. A.; Chaoui, K.; Mabrouki, T.; Rigal, J. F. 2012. Analysis of surface roughness and cutting force components in hard turning with $\mathrm{CBN}$ tool: prediction model and cutting conditions optimization, Meas. J. Int. Meas. Confed. 45: 344-353. https://doi.org/10.1016/j.measurement.2011.11.011.

16. Motorcu, A. R. 2009. Surface roughness evaluation when machining carbon steel with ceramic cutting tools, Journal of the Faculty of Engineering and Architecture of Uludağ University 14: 139-145. https://doi.org/10.17482/uujfe.21390.

17. Makadia, A. J.; Nanavati J. I. 2013. Optimisation of machining parameters for turning operations based on response surface methodology, Measurement 46: 15211529. https://doi.org/10.1016/j.measurement.2012.11.026.

18. Ericsen, E. 1998. Influence from production parameters on the surface roughness of a machined short fibre reinforced thermoplastic, International Journal of Machine Tools \& Manufacture, 39: 1611-1618. https://doi.org/10.1016/S0890-6955(99)00017-6.

19. Taguchi, G.; Elsayed, E.; Hsiang, T. 1989. Quality Engineering in Production Systems, McGraw-Hill, Books, 235-241. New York.
20. Köklü, U. 2013. Optimisation of machining parameters in interrupted cylindrical grinding using the Greybased Taguchi method, International Journal of Computer Integrated Manufacturing 26: 696-702. https://doi.org/10.1080/0951192X.2012.749537.

21. Ross, P. J. 1998. Taguchi Techniques for Quality Engineering, Mc-Graw-Hill, New York.

22. Yoon, H. S.; Wu, R.; Lee, T. M.; Ahn, S. H. 2011. Geometric optimization of micro drills using Taguchi methods and response surface methodology, Int. J. Precis. Eng. Manuf. 12: 871-875. https://doi.org/10.1007/s12541-011-0116-6.

23. Korkut, I.; Boy, M.; Karacan, I.; Seker, U. 2007. Investigation of Chip-back temperature during machining depending on cutting parameters, Materials and Design 28:2329-2335. https://doi.org/10.1016/j.matdes.2006.07.009.

24. Outeiro, J. C.; Umbrello, D.; M'Saoubi, R. 2006. Experimental and numerical modelling of the residual stresses induced in orthogonal cutting of AISI 316L steel, International Journal of Machine Tools and Manufacture 46: 1786-1794.

https://doi.org/10.1016/j.ijmachtools.2005.11.013.

25. Koçak, H.; Gülesin, M.; Uzun, G. 2014. GGG 90 Küresel Grafitli Dökme Demirin İşlenebilirliğinin Kesme Kuvvetleri ve Yüzey Pürüzlülüğü Açısından Değerlendirilmesi, $2^{\text {nd }}$ International Symposium on Innovative Technologies in Engineering and Science, 295302.

\section{M. Özdemir}

\section{OPTIMIZATION WITH TAGUCHI METHOD OF INFLUENCES ON SURFACE ROUGHNESS OF CUTTING PARAMETERS IN CNC TURNING PROCESSING}

\section{S u m m a r y}

In this study, the effect of cutting speed, feed rate, and depth of cut on surface roughness was experimentally examined in the processing of AISI 409 (ferritic chromium stainless steel) material. As cutting parameters, three cutting speeds $(200,300$, and $400 \mathrm{~m} / \mathrm{min})$, three feed rates $(0.1,0.2$, and $0.3 \mathrm{~mm} / \mathrm{rev})$, and three depths of cut $(1,2$ and $3 \mathrm{~mm})$ were selected. Turning tests in CNC machine were made according to Taguchi L27 orthogonal array and the signal/noise $(S / N)$ ratios were used in the evaluation of the experimental results. By using Taguchi method, cutting parameters giving the optimum surface roughness ( $R a$ and $R z$ ) values were determined. The effect of control factors on the results was found with the help of Analysis of Variance (ANOVA). According to ANOVA results, the most important parameters affecting the surface roughness were determined as feed rate, depth of cut, and cutting speed, respectively. By conducting validation tests, the optimization was observed to be applied successfully.

Keywords: machinability, surface roughness, cutting parameters, Taguchi method, ANOVA.

Accepted March 22, 2019

Received October 14, 2019 